\section{Trigeminothalamic Tracts}

John E. Mendoza

Department of Psychiatry and Neuroscience, Tulane Medical School and SE Louisiana

Veterans Healthcare System, New Orleans, LA, USA

\section{Definition}

Trigeminothalamic tracts refer to brainstem pathways from the spinal nucleus of $\mathrm{V}$ (trigeminal nerve) and the principal (chief) nucleus of $\mathrm{V}$ to the ventral posterior medial nucleus of the thalamus. Two separate trigeminothalamic tracts have been identified: a ventral and a dorsal tract. The ventral and larger of the two tracts is derived from both of these nuclei. Once these fibers leave the nuclei, they cross the midline and travel in proximity to the fibers of the medial lemniscus to the thalamus. The dorsal trigeminothalamic tract originates only from the principal nucleus of $\mathrm{V}$ and travels ipsilaterally to the thalamus. Brainstem lesions affecting the ventral trigeminothalamic tract, in particular, are likely to result in sensory changes in the contralateral face.

\section{Cross-References}

- Principal Sensory Nucleus of V

- Spinal Nucleus of V

\section{References and Readings}

Wilson-Pauwek, L., Akesson, E. J., Stewart, P. A., \& Spacey, S. D. (2002). Cranial nerves in health and disease. Hamilton: B.C. Decker. 